\title{
A atividade de Inteligência nos novos documentos de Defesa do Brasil
}

\author{
The Intelligence activity \\ in the new documents of Defense of Brazil
}

Rev. Bras. Est. Def. v. 4, nº 2, jul./dez. 2017, p. 101-124

\section{ALEXANDRE DE OLIVEIRA MARTINS}

\section{INTRODUÇÃO}

Os eventos ocorridos em 2001 nos EUA evidenciaram certa debilidade dos serviços de inteligência em evitar atentados não convencionais, como aqueles que passaram a utilizar aeronaves comerciais, caminhões ou automóveis como armas. Tanto órgãos de Segurança quanto de Defesa perceberam relativamente inúteis ações tradicionais para neutralizar ameaças atípicas. Ainda que os anos seguintes a 2001 tenham sido marcados pela retórica belicista do governo de George W. Bush, a chamada Guerra ao Terror não evitou, na sequência, outros atentados em território de países alinhados aos EUA: Madri (2004), Londres (2005), Paris (2015), Nice (2016), Bruxelas (2016) e, novamente, Londres (2017), confirmando, assim, a esterilidade de ações clássicas contra práticas violentas incomuns. Na busca por superar as fragilidades de ações isoladas dos serviços de inteligência e observando ligações entre corrupção, crime organizado transnacional, tráfico de pessoas e financiamento ao terrorismo, os Estados, também regionalmente mas sobretudo no âmbito das Nações Unidas, aprovaram convenções que passaram a destacar ações de inteligência tanto no combate a ilícitos quanto na prevenção de atos terroristas: entrega controlada, confisco de bens, vigilância eletrônica, infiltração policial, monitoramento financeiro e força-tarefa. É o caso principalmente da Convenção de Palermo, adotada em 2000, mas em vigor a partir de 2003, e da Convenção de Mérida, adotada em 2003, mas em vigor em 2005. Por seu lado, a Convenção Internacional para a Supressão do Financiamento do Terrorismo, adotada em 1999, mas em vigor a partir de 2002, exortou os Estados a intensificarem o intercâmbio

Alexandre de Oliveira Martins - Universidade de São Paulo. 
de informações sobre a movimentação de ativos suspeitos, dando, portanto, destaque à inteligência financeira.

Referidas convenções enfatizam que o enfrentamento de crimes e a prevenção de atos terroristas pressupõem, num mundo globalizado e em rede, cada vez mais cooperação e coordenação, tanto no cenário nacional quanto internacional. No segundo caso, Convenções, Tratados e Acordos são os instrumentos disponíveis no Direito Internacional para a concretização das intenções. No primeiro caso, a Constituição, as Leis e as Políticas Públicas funcionam como balizas da forma como deve se dar a cooperação entre órgãos de segurança e defesa no âmbito do Direito doméstico. A atividade de inteligência constitui o principal elemento em tal cooperação dada sua dupla função, informacional e coercitiva. Esse caráter de elo ocorre em virtude da origem tripla da atividade: a diplomacia, o fazer a guerra e o policiamento. No caso do Brasil, a importância da atividade de inteligência na diplomacia pode ser percebida pelos documentos internacionais dos quais o país é signatário, como as convenções referidas. As cooperações jurídicas internacionais e a interação das forças de segurança em âmbito interno realçam a importância da inteligência no policiamento. E é nos Documentos de Defesa que se pode observar a forma como a inteligência é abordada pelo 'fazer a guerra'.

Considerando tal quadro, este trabalho buscará responder: i) como a Atividade de Inteligência é abordada nos Novos Documentos de Defesa do Brasil? ii) como a Defesa propõe-se a cooperar e a interagir com a Atividade de Inteligência? iii) como a Atividade de Inteligência propõe-se a cooperar e a interagir com a Defesa? À primeira questão obter-se-á a resposta a partir de descrição seguida de análise dos Novos Documentos de Defesa. Já a resposta aos outros dois questionamentos passa por uma comparação entre os Novos Documentos de Defesa e os Documentos de Inteligência. Procurando, portanto, seguir o percurso indicado pelas perguntas, o artigo estrutura-se em três partes, com suas respectivas subdivisões. Na primeira, inicialmente discute-se o que é um documento de Defesa e qual seria sua natureza para, após, proceder a uma descrição sintética das minutas de 2016, comparando-as com as versões oficias de 2012. Na segunda parte, faz-se uma rápida apresentação sobre o conceito de Inteligência e, ainda, um breve resumo do histórico da atividade no Brasil, além de se descrever os principais pontos da Política Nacional de Inteligência (PNI) e da Estratégia Nacional de Inteligência (ENINT). A terceira parte dedica-se a entrelaçar as duas primeiras, com destaque para os principais pontos dos Novos Documentos de Defesa que abordam a atividade de Inteligência; nesta parte terceira, abordam-se também as correlações entre as minutas de Defesa de um lado e a PNI e a ENINT de outro. Ao final, são relatadas as conclusões. 


\section{PARTE 1 - DOCUMENTOS DE DEFESA}

\section{Perspectivas interna e externa}

Em sentido lato, considera-se documento a declaração, normalmente escrita, reconhecida em termos oficiais em virtude, sobretudo, da autoridade de seu emissor. É a institucionalidade do generante que legitima a mensagem gerada, acabando essa por se coligir como autêntica e constituinte de informação relevante e, a priori, verdadeira. Um Documento de Defesa, por evidente, restringe o significado de documento ao âmbito da Defesa, aqui compreendida como a área estatal responsável pela proteção do nacional em variadas esferas de uso de forças específicas. O Estado, como resultante do contrato social efetivado por seus partícipes, transfere a legitimidade recebida ao Documento de Defesa que produz. A Defesa, assim, em virtude do monopólio da coerção que o Estado detém, é a faceta abalizada para realizar a proteção do próprio Estado nacional. Pelo fato de proteção implicar organização, planejamento e especialização, a Defesa normalmente é constituída e executada por militares, as forças garantidoras da existência do Estado perante outros Estados. Os Documentos de Defesa, entretanto, não são produtos exclusivos de debates militares, senão dos diversos, e muitas vezes conflitantes, setores sociais que disputam a hegemonia pela administração dos recursos do Estado. Em um Documento de Defesa, há, em constante interação, um viés interno, reflexo das tensões entre os diferentes grupos que compõem a sociedade e disputam o gerenciamento do Estado, e um viés externo, reflexo da intenção de dirimir desconfianças de outros Estados sobre as intenções do Estado emissor.

Da perspectiva interna, um Documento de Defesa é o quociente de consenso doméstico, transformando-se em "um instrumento estável facilitador da convergência de expectativas de comportamentos e ações [...] para a consecução de objetivos politicamente determinados” (Raza 2004, 335). Esse consenso deve assegurar o "os determinantes da prática profissional militar com os requisitos políticos que regulam o uso da força” (Raza 2004, 341). Da perspectiva externa, um Documento de Defesa pode amenizar o estado de insegurança internacional. O conhecido 'dilema de segurança', de John Herz (1950), discute a possibilidade de conflito violento entre dois ou mais atores estatais quando um, ao argumentar que elevará suas capacidades militares por razões defensivas, faz com que o outro se arme, esse alegando interesse nacional e/ou procura de equilíbrio, gerando um movimento circular conhecido como 'escalada de conflito'. A difusão de intenções - mecanismo que leva à adoção de políticas públicas pelos Estados - terá maior ou menor propensão em amenizar a insegurança em função 
“do número de interações, da proximidade geográfica dos Estados e o grau de educação sobre assuntos de segurança e defesa dos líderes nacionais e da população em geral” (Raza 2004, 342). Da perspectiva externa, portanto, um Documento de Defesa, pela sensibilidade do tema e pelo compromisso com a transparência, ao mesmo tempo em que ameniza desconfianças, dirimindo as suposições das intenções malignas dos atores, também pode aumentar a cooperação entre Estados geograficamente próximos ou cujas interações sejam constantes.

De maneira simplificada os Documentos de Defesa podem tomar a forma de Políticas Nacionais de Defesa, que estipulam os objetivos da Defesa do Estado gerador do documento; podem ainda ganhar a forma de Estratégias Nacionais de Defesa, que orientam o Estado sobre o que fazer para alcançar aqueles objetivos; e podem, por fim, tomar a forma de Livros Brancos, que são descrições ou marcos cujas intenções são tornar transparentes os assuntos de Defesa. Com a finalidade de observar como os setores nacionais brasileiros foram direcionados em benefício da Defesa, far-se-á na sequência uma breve descrição dos Novos Documentos em sua versão preliminar de 2016.

\section{Política Nacional de Defesa (PND), Estratégia Nacional de Defesa (END) e Livro Branco de Defesa Nacional (LBDN) - minutas - BRASIL - 2016}

Na primeira das cinco partes da PND-2016, delineia-se a trajetória da contínua defesa do país, desde 1996, quando foi aprovada a Política de Defesa Nacional (PDN), passando por 2005, quando surgiu a END, até 2012, quando então recebeu a denominação de PND. A parte dois, subdividida em outros três segmentos, expõe, em 2.1, o contexto da PND, narrando seus fundamentos: ameaças externas, percepção de Segurança Nacional, coordenação do Ministério da Defesa, inseparabilidade do desenvolvimento nacional, solução pacífica de controvérsias, priorização da América do Sul, Atlântico Sul, costa ocidental africana e Antártica, interesse na América do Norte, Europa e mar do Caribe. Em 2.2, aborda-se o ambiente nacional, salientando a Constituição, a integração e coesão nacionais, o desafio do estrangulamento de infraestruturas existentes, a falta de regularidade nas aquisições de Produtos de Defesa, a possibilidade de cooperação com nações mais avançadas no campo tecnológico, a tradição diplomática brasileira, a estabilidade político-institucional, a garantia da soberania, a inserção internacional, a Amazônia, o Atlântico Sul, o potencial hidroenergético, a biodiversidade, as fronteiras, a vocação marítima, o espaço aéreo, o ambiente cibernético, a expansão da matriz energética e a preocupação com áreas onde se localizam tanto o poder político e econô- 
mico quanto as maiores densidades demográficas. No item 2.3, examina-se o ambiente internacional, com proeminência para a globalização e a interdependência, para a assimetria de poder, para a guerra irregular e híbrida, para as disputas marítimas, espacial e por fontes de água doce, alimentos e energia, para o desenvolvimento sustentável, para as soluções negociadas, para a importância de operações internacionais, para a dependência de sistemas de informações, gerenciamento e comunicações, para o incremento da cooperação entre os países sul-americanos, para as ações alinhadas e indivisíveis de todos os setores governamentais. A terceira parte dedica-se a especificar a concepção política de Defesa, essencialmente ligada ao desenvolvimento e à diplomacia. A penúltima parte esboça os objetivos de Defesa: garantia da soberania, do patrimônio nacional e da integridade territorial, a capacidade de Defesa para a missão constitucional das Forças Armadas, a salvaguarda de pessoas, bens, recursos e interesses nacionais situados no exterior, a preservação da coesão e unidade nacionais, a estabilidade regional e para a paz e segurança internacionais, o incremento da projeção do Brasil no concerto das nações, a autonomia produtiva e tecnológica na área de defesa e a ampliação e envolvimento da sociedade brasileira nos assuntos de Defesa Nacional. Na última parte, são feitas considerações como a necessidade de articulação entre todos os setores da Administração Federal e a as ações presentes na END, que definem como os objetivos da PND são concretizados.

A primeira das quatro partes da END-2016 desenvolve uma introdução em que se ressalta novamente o percurso da Defesa Nacional e a importância das estratégias que devem nortear a sociedade brasileira nas ações de defesa. A segunda parte reafirma a concepção estratégica de Defesa, intimamente ligada à Carta Magna, à Diplomacia e à Segurança. A parte três, subdividida em outras três, discorre em primeiro lugar sobre o Poder Nacional, destacando as Capacidades Nacionais de Defesa (Proteção, Dissuasão, Pronta-Resposta, Coordenação e Controle, Gestão da Informação, Mobilidade Estratégica, Mobilização), depois, em segundo lugar, discute as ações de diplomacia, dando relevo à antecedência das relações diplomáticas frente ao uso da força militar; em terceiro lugar, descreve o setor de Defesa, com destaque para o Plano de Articulação e Equipamentos de Defesa, para a Marinha do Brasil, para o Exército Brasileiro, para a Força Aérea Brasileira e para os setores Nuclear, Cibernético e Espacial. Por fim, a quarta parte apresenta as estratégias e ações estratégicas de Defesa, organizadas conforme os Objetivos Nacionais de Defesa, assim, para cada um dos objetivos descritos na PND, são estabelecidas Estratégias de Defesa (ED) que incorporam várias Ações Estratégicas de Defesa (AED). O documento é encerrado com a apresentação de um glossário. 
A primeira das seis partes do LBDN-2016 dispõe sobre as relações entre o Estado brasileiro e a Defesa Nacional, chamando a atenção para os princípios básicos do Estado e para a conexão entre política externa e de defesa. A segunda parte analisa o ambiente estratégico do século XXI, frisando a correlação entre sistemas regionais e o sistema internacional, além de apresentar regimes e tratados internacionais com reflexos para a defesa, como desarmamento, não proliferação nuclear, controles de exportação de bens sensíveis, Antártica, mar e espaço exterior, meio ambiente e novas tecnologias da informação e da comunicação. A terceira parte apresenta a estrutura de Defesa e o instrumento militar, detalhando o organograma das diversas instâncias que compõem a Defesa Nacional. A quarta parte correlaciona Defesa e Sociedade, destacando os pontos de contato da Defesa com os esportes, com os poderes constituídos, com os direitos humanos, com a Academia, com o Programa Antártico Brasileiro e com o desenvolvimento industrial. A penúltima parte dedica-se a mostrar a transformação da Defesa, sua modernização e o pessoal civil presente na administração central do Ministério da Defesa. Por fim, a última parte, antes dos Anexos, destaca a Economia de Defesa, com o orçamento e os demonstrativos de gastos em Defesa. Se comparadas, a descrição das minutas mostra que houve algumas alterações em relação aos documentos de defesa oficiais de 2012. Tais diferenças serão apontadas a seguir.

\section{Principais diferenças entre os documentos de 2012 e as minutas de 2016}

Em termos de conteúdo, a PND-2012 parece dar maior destaque ao ambiente regional e ao entorno estratégico, enquanto a minuta de 2016 dilui a preocupação regional no contexto maior do cenário internacional. O menor destaque regional também pode ser percebido na forma como os objetivos nacionais de defesa são apresentados: enquanto em 2012 a 'contribuição para a estabilidade regional' (item IV) e a 'paz e segurança internacionais' (item V) constituíam, cada uma, um objetivo específico, elas foram mescladas na minuta de 2016. Tem-se a impressão de que os objetivos VII e XI, de 2012, foram fundidos no objetivo dois de 2016, implicando compreender que o documento de 2016 não separa, como o de 2012, logística e mobilização das Forças Armadas de modernização, integração, adestramento e profissionalização. A PND-2012 faz menção direta à importância do arranjo BRICS para o Brasil, enquanto a minuta de 2016 deixa tal importância sugerida. As alterações de uma PND para outra possibilitam deduzir a maior relação existente entre Defesa e Diplomacia nos documentos de 2016, de modo que a mudança dos interesses da Política Externa Brasileira é quase imediatamente refletida na perspectiva da Defesa. É possível que 
a modificação ocorrida no comando do país em agosto de 2016 explique a reorganização das inclinações da Política Externa Brasileira, que parece ter redirecionado aspectos então vinculados à gestão anterior, como a ênfase nos BRICS e o realce à integração regional. As PND, portanto, carregam também particularidades de cada momento político que as gerou.

Entre a END-2012 e a minuta da END-2016 percebem-se duas diferenças fundamentais: 1) se o documento de 2012, por meio de um tópico especial, dá ênfase à correlação entre a Estratégia Nacional de Defesa e a Estratégia Nacional de Desenvolvimento (páginas 43-44), o de 2016 dedica apenas um parágrafo da segunda parte à menção sobre a relação Desenvolvimento/ Defesa (página 17); 2) o documento de 2012, também por meio de tópico único, destaca a Inteligência de Defesa (páginas 133-134), enquanto a minuta de 2016 dá destaque, em vários momentos, à preocupação com o ambiente cibernético (página 31, por exemplo), e com o Sistema Brasileiro de Inteligência (Sisbin). As END parecem ser os documentos privilegiados para o entendimento das duas mudanças mais significativas ocorridas no intervalo de quatro anos no setor de Defesa. A primeira diz respeito ao vínculo estabelecido entre Defesa e Desenvolvimento. Em 2012, a PND enfatizava a simultaneidade da Estratégia Nacional de Desenvolvimento em relação à Estratégia Nacional de Defesa, de maneira que aquela deveria motivar essa, concebendo a Defesa como parte de um só todo social. Havia ênfase na vinculação entre o desenvolvimento do país e o desenvolvimento da Defesa. O documento de 2016, embora afirme a inseparabilidade das duas estratégias, prioriza a ação diplomática, especificando que a concepção estratégica de defesa do Brasil liga-se aos propósitos da Diplomacia ao interagirem com as contrapartes de outros países. Desprega-se, assim, de um viés 'para dentro' presente no documento anterior. Esta parece ser uma mudança bastante importante por inverter as bases da concepção estratégica de defesa: de uma perspectiva interna (desenvolvimento) para uma perspectiva externa (diplomacia); de uma ideia totalizante (o país) para uma ideia setorial (a política externa). A segunda mudança envolve diretamente a atividade de inteligência. Em 2012, antes, portanto, de vir à tona a espionagem estadunidense, a END registra a importância da Inteligência de Defesa, dando, entretanto, pouca ênfase ao Sistema Brasileiro de Inteligência e à Abin. A minuta da END-2016 amplia o escopo da atividade de inteligência de Estado, abordando-a também no interior do setor de Defesa, mas destacando o caráter orgânico e estratégico que a atividade deveria ter na dinamização de informações no todo estatal. Não por outro motivo, o documento chama a atenção para a importância do Sisbin e a função relevante que a Defesa ocupa dentro dele. Essa parece ser outra mudança muito importante de um documento de defesa para outro pelo caráter essencial que 
dá à inteligência de Estado (Abin) e ao Sisbin, incorporando a Defesa numa dinâmica na qual ela parecia não estar presente em 2012.

Cotejando os dois LBDN, vê-se que são os documentos mais semelhantes, embora o de 2016 não apresente nos anexos informações sobre Equipamentos de Defesa, tampouco dados mais detalhados sobre o Plano de Articulação e Equipamento de Defesa (PAED). Em termos de conteúdo, sobre os números apresentados no tópico Economia de Defesa, chama atenção a diferença existente entre os dados de 2012 e 2016: enquanto 46,3\% do gasto total do Ministério da Defesa em 2011 era para pagamento da previdência de inativos e pensionistas, em 2015 esse número (identificado como Encargos Sociais) sobe para 46,5\%; aumento semelhante é percebido entre os $31,5 \%$ de 'apoio administrativo' de 2011 e os 35,9\% da 'gestão e manutenção do Ministério da Defesa', em 2015; esses aumentos parecem refletir a queda de investimento e custeio no reaparelhamento e adestramento das Forças de 2011 (10,8\%) para 2015 (10,5\%). Os dados mostram também que o Brasil caiu uma posição se comparados os números de 2011 e 2015 no que diz respeito aos países com maiores gastos em defesa no mundo: respectivamente de décimo lugar $(35,4$ bilhões de dólares) para $11^{\circ}$ (31,95 bilhões de dólares), segundo dados do Instituto de Pesquisa de Paz Internacional de Estocolmo (Sipri). Proporcionalmente, o Brasil deixou de gastar em Defesa 1,5\% do PIB em 2011 para gastar 1,4\% em 2015. Sobre os quantitativos militares, observa-se uma queda de 2012 para 2015: de 339.365 para 335.707, comprometendo o objetivo do Plano Brasil 2022 (citado apenas nos documentos de 2012). Percebe-se também certa inversão entre os quantitativos militares em missões de paz e adidos militares no Exterior: em 2012 estavam em missões de paz 2.444 militares, ao passo que em 2016 esse número caiu para 1.299; por outro lado, os adidos subiram de 175 em 2012 para 240 em 2015. Esses últimos números são particularmente importantes porque sugerem as diferentes estratégias da área de Defesa em relação à atividade de inteligência. Se, por um lado, em 2016, houve queda de quase $50 \%$ na quantidade de militares em missões de paz em relação a 2012, em 2015 houve aumento de quase $40 \%$ de adidos militares em serviço no exterior em relação a 2012. Embora os dados não façam menção direta, é de se supor que tais números traduzam a maior importância que o setor de Defesa passou a dar à atividade de inteligência, já que uma das funções das adidâncias no exterior é justamente o trabalho relacionado a ações de inteligência. Essa suposição é corroborada quando se analisam mais detidamente a Política Nacional de Inteligência (PNI) e a Estratégia Nacional de Inteligência (ENINT). Antes de abordá-las mais detidamente, no entanto, faz-se necessária uma breve introdução sobre o conceito de inteligência, o que se passa a fazer a seguir. 


\section{PARTE 2 - ATIVIDADE DE INTELIGÊNCIA}

\section{Conceito}

A conceito de 'inteligência' pode variar conforme o foco que se queira dar e conforme os próprios objetivos, valores, ideologias, estratégias e momento histórico de seus enunciantes, uma vez que defini-lo é explicitar a prática que se deseja oculta. Sherman Kent, em 1949, por exemplo, considerava inteligência de segurança (security intelligence) "a informação que trata continuamente de identificar agentes clandestinos enviados ao país por potências estrangeiras [...] que identifica traidores nascido no país e pessoas que violam a lei federal” (Kent 1949, 210). Já para a Inglaterra do século XIV - então uma pequena potência, entre outros maiores e mais poderosos reinos europeus, que consideravam o reino insular um rival -, inteligência era "informações sobre o que estava acontecendo dentro das cabeças coroadas de outros reinos" (Volkman 2013, 55-56). Nota-se, então, que o conceito de inteligência, a depender da restrição que se queira fazer (inteligência [de] $\mathrm{X})$ e das ameaças que ocupam as preocupações de seus enunciantes, pode receber variadas acepções, mas correlacionadas à informação.

Apesar da variação focal, temporal, espacial e política, um núcleo duro semântico parece ser consensual. Para Sherman Kent (1949, 151), inteligência é uma trindade: produto (conhecimento produzido a partir de informações processadas), organização (estruturas funcionais) e atividade ou processo (meios). A primeira definição de Kent coaduna-se, em sentido amplo, com a concepção de Volkman (2013, 7), de que "inteligência é informação processada" e assemelha-se à de Cepik (2001, 24), de que "inteligência é conhecimento ou informação analisada”, que, por sua vez, aproxima-se da de Ugarte (2002), para quem inteligência é "um produto sob a forma de conhecimento ou informação elaborada, cuja função é estatal, realizada por uma organização ou conjunto de organizações, e com caráter secreto", também em consonância com a de Gonçalves (2008, 138), cuja convicção é a de que "inteligência seria a informação processada e analisada com o objetivo de assessorar o processo decisório”.

Comum a todas as definições observa-se o vocábulo 'informação’. Ele torna-se, portanto, a palavra-chave que ata diferentes concepções de inteligência. De igual maneira, outro traço incondicional da atividade é a particularidade do segredo. Eis, então, o núcleo duro da atividade: a informação e o segredo. No Brasil, a Política Nacional de Inteligência (PNI) faz distinção entre três conceitos: atividade de inteligência, inteligência e contrainteligência. Tais conceitos e suas definições parecem evitar termos que façam referência a ou aventem o núcleo duro da atividade, 
isto é, informação e segredo. Esse procedimento possivelmente advém do conjunto de imagens a que se vinculou a atividade durante os anos de regime autoritário brasileiro entre as décadas de 1960 e 1980 . Incluído nesse conjunto estava o monitoramento de cidadãos realizado pelo Serviço Nacional de Informação (SNI), de maneira que, posteriormente, a atividade passou a ser associada à ideia de limitação da privacidade individual. É por isso que o assunto provoca reações distintas, ambas importantes de se analisar para que se compreenda o passado e se debata profundamente a importância da atividade em e para um Estado democrático de direito. Na democracia brasileira, a atividade de inteligência é atualmente objeto de controle interno - Câmara de Relações Exteriores de Defesa Nacional (Creden) e Controle Interno Setorial (Ciset) - e externo - Comissão Mista do Congresso Nacional (CCAI) e Tribunal de Contas da União (TCU)-, supervisões inexistentes anteriormente. Um breve histórico da atividade no Brasil oferece um panorama das visões antagônicas que a atividade suscita em âmbito nacional. É o que se verá nas seções seguintes.

\section{O Brasil e a Atividade de Inteligência}

A percepção sobre o funcionamento da Atividade de Inteligência no Brasil pode variar, condicionada ao fato de se estar do lado da recepção da atividade ou da produção. Entende-se por recepção o sentimento do brasileiro que, pela própria experiência ou por análise histórica, associa a atividade à coerção do Estado sobre seus nacionais. Por produção entende-se a prática e reflexão teórica de todos aqueles ligados à área de inteligência, seja em nível governamental ou acadêmico. Os primeiros tenderão a ter resistência sobre a necessidade de serviços de inteligência. Os segundos, ainda que de forma crítica, terão poucas dúvidas sobre a importância da existência de serviços de inteligência de Estado. Essa divisão parece vir se alterando a partir de 2001, com a queda das torres gêmeas, e após 2013, quando o sistema de espionagem estadunidense foi revelado. Os acontecimentos de 2001 acabaram por ressaltar a necessidade de o Estado se antecipar a ataques terroristas, função que em tese só poderia ser exercida pela atividade de inteligência. Como consequência, por um lado, houve incremento do orçamento do setor de inteligência estatal, por outro, houve, ainda que de forma crítica, maior aceitação da atividade pela sociedade. As revelações de espionagem em 2013, por envolver o Brasil, apontaram as dificuldades da contrainteligência brasileira em neutralizar interferências externas em assuntos nacionais, o que igualmente gerou no país debate mais amplo sobre a importância da atividade. 
Outro fator importante na percepção sobre o funcionamento da Atividade de Inteligência no Brasil é o papel exercido pelos serviços de informação da e na América do Sul durante a chamada Operação Condor, nos anos 1970/80. Esse período temporal acabou estabelecendo uma vinculação direta entre sistemas de vigilância/inteligência e repressão. Tal prática foi responsável por violações de direitos humanos, como apontadas, por exemplo, nos relatórios da Comissão Nacional da Verdade (CNV), do Brasil (2014). A compreensão dessa peculiar forma de cooperação entre agências de inteligência sul-americanas, intitulada também de Operativo Condor, passa pelo entendimento da divisão do mundo em dois blocos ideológicos antagônicos durante a Guerra Fria e a peculiaridade da revolução cubana de 1959, que, em última instância, tornou-se o epicentro da preocupação estadunidense com a ampliação pelo continente americano da ideologia oposta à sua, mais tarde novamente materializada no apoio à supressão de Salvador Allende do poder no Chile, em 1973. O fim da URSS e a consequente cessação da Guerra Fria colocaram os países sul-americanos, então sob contexto de redemocratização, diante do dilema de reestruturar seus serviços de inteligência à luz do controle democrático e baixo o desafio de dissociar a imagem da atividade do aparato repressor do passado.

Desafio importante que se interpõe entre a sociedade e a atividade de inteligência no Brasil, portanto, é simultaneamente a superação do passado recente, marcado pela Operação Condor e pela Doutrina de Segurança Nacional (DSN), e o reconhecimento da indispensabilidade de um serviço de inteligência nacional ágil, transparente, eficiente e eficaz, num cenário internacional cada vez mais caracterizado, por um lado, pelos conflitos de interesses estatais e, por outro, pela necessidade de cooperação e compartilhamento de informações no enfrentamento a ilícitos transnacionais e a atividades de financiamento ao terrorismo.

A convergência entre o passado e o futuro no caso da atividade de inteligência no Brasil certamente passa pelo entendimento do caráter histórico da atividade. E historicamente o que se pode observar é que, pela origem dos serviços de informações brasileiros estar fortemente vinculada ao setor de Defesa, é difícil traçar o histórico de um sem fazer menção ao outro. Na sequência, descreve-se um curto histórico da atividade no Brasil com o fim de contextualizar o processo por meio do qual a atividade de inteligência de Estado tomou a forma atual (Sisbin e Abin).

\section{Do Conselho de Defesa Nacional à Estratégia Nacional de Inteligência}

Para Oliveira (2010), o processo constitutivo da atividade de informações no Brasil foi iniciado em 1927, com decreto criando o Conselho 
de Defesa Nacional (CDN), órgão consultivo vinculado à Presidência da República. Em 1937, a Constituição do Estado Novo instituiu o Conselho de Segurança Nacional (CSN). O governo de Getúlio Vargas seria derrubado em 1945 e o general Eurico Gaspar Dutra, seu antigo Ministro da Guerra, eleito. Eurico Dutra consideraria insuficiente grande parte da estrutura legal instaurada pela Constituição de 1937, inclusive o CSN, assim, também por decretos, em 1946, dividiria a Secretaria Geral do CSN em três seções, sendo a segunda a responsável pela coordenação do Serviço Federal de Informações e Contrainformações (SFICI), só implementado em 1958, no governo de Juscelino Kubitschek. Em 1964 seria criado o Serviço Nacional de Informação (SNI), subordinado diretamente à Presidência e subsidiário do CSN em questões atinentes à segurança nacional. A Constituição de 1988, não mencionando os vocábulos "informação" ou "inteligência”, registrou a existência de diversos órgãos com atuação conexa à da inteligência, mas sem fazer menção ao SNI. Em 1997 seria apresentado ao Congresso Nacional um projeto de lei que regulamentava a atividade de inteligência e propunha a criação do Sistema Brasileiro de Inteligência (Sisbin), cujo órgão central seria a Agência Brasileira de Inteligência (Abin). Pouco antes, uma medida provisória, transformaria a Casa Militar em Gabinete de Segurança Institucional (GSI), parte constitutiva da Presidência da República, cujo chefe possuiria honras e prerrogativas de Ministro de Estado. Em 1999, a Lei 9.883 instituiria o Sisbin, regulamentado em 2002, e criaria a Abin. Em 2004 é autorizada a realização de concurso público para a contratação de analistas de informações e em 2005 são integrados ao corpo funcional os primeiros egressos dos Cursos de Formação em Inteligência (CFI) do certame. Em 2009 seria criado o Comitê Interministerial para elaboração da Política Nacional de Inteligência (PNI) - prevista no artigo quinto da lei de criação do Sisbin. Em junho de 2016, seria fixada a Política Nacional de Inteligência. Em dezembro de 2017 seria aprovada a Estratégia Nacional de Inteligência. Em 2018, outro concurso seria aberto para o preenchimento de quadros.

Esse breve histórico, além de apresentar datas importantes para a atividade de inteligência, também evidencia o forte vínculo entre a inteligência de Estado e a Defesa, já que a origem da formalização da atividade no país está localizada no CDN. Ademais, a PNI e a ENINT traduzem a dinâmica atual da atividade de inteligência no Brasil: quase vinte anos depois da criação da Abin, a fixação da PNI e a aprovação da ENINT respondem a circunstâncias nacionais e internacionais já mencionadas, como tornar os serviços de inteligência mais ágeis e transparentes (âmbito doméstico), mas também buscam fazer frente a ilícitos transnacionais, financiamento do terrorismo e inteligências adversas (âmbito internacional). $\mathrm{O}$ 
incremento da contrainteligência (neutralização da inteligência externa) é também uma resposta aos questionamentos levantados durante a CPI da Espionagem, uma consequência direta no Brasil das revelações de 2013. A referida CPI buscou identificar falhas nos sistemas de inteligência e contrainteligência e de proteção de dados virtuais. De acordo com seu relatório final, não foi possível confirmar a materialidade de crime, de modo que as investigações teriam restado inconclusas. A importância da CPI teria sido mais no sentido de ter feito uma primeira avaliação dos sistemas brasileiros de inteligência e de segurança das comunicações. Durante os debates, abordou-se desde a importância da inteligência tecnológica e a necessidade de se estabelecer uma agência de inteligência de sinais até a organização, crise e aprimoramento da atividade no Brasil, passando pelo papel do Parlamento no fortalecimento do controle da atividade de inteligência e pela necessidade de alteração na legislação infraconstitucional de inteligência. O relatório final da CPI também apresentou recomendações: 1) publicar a Política Nacional de Inteligência (PNI); 2) investir em contrainteligência; 3) aumentar a dotação orçamentária para a comunidade de inteligência; 4) criar a agência brasileira de inteligência de sinais; 5) estabelecer a Política Nacional de Inteligência de Sinais, a Estratégia e os Planos Nacional e Setorial, em sintonia com a PNI e a PND;6) criar uma comissão temporária, no âmbito do Senado Federal, para propor reformas na legislação brasileira de inteligência; 7) aprovar a PEC 67/2012 (que eleva a atividade de inteligência ao nível constitucional); 8) aprofundar os mecanismos de controle externo da atividade de inteligência.

Com a fixação da PNI em 2016, a aprovação da ENINT em 2017 e a realização de concurso público para a Abin em 2018, as recomendações 1, 2, 3, parte da 5 e 8 parecem já ter sido atendidas. A recomendação 4 e parte da 5 , por pressuporem tempo e exigirem confluência entre Defesa e Inteligência, insinuam não ocorrer no curto prazo, embora sua implementação possa ser acompanhada pelas PND, PNI, END e ENINT. A recomendação 7, diretamente ligada à 6, está em processo, vez que a PEC 67/2012 está ainda em tramitação na Comissão de Constituição, Justiça e Cidadania do Senado Federal, conforme última atualização em dezembro de 2017. Como se pode observar, alguns eventos interferem com maior intensidade na atividade de inteligência, acelerando seu processo de formalização. Diferentemente do que ocorre em regimes autoritários, entretanto, a democracia favorece um avanço baseado em maior transparência e publicidade, salvaguardando a dignidade da pessoa e os direitos humanos. Ademais, constata-se que, no Brasil, mesmo na democracia, são os impulsos externos que acabam por acelerar o desenvolvimento da atividade, como restou provado pelos desdobramentos da CPI da Espionagem. 
Descritos os Novos Documentos de Defesa e sintetizado o histórico da atividade de inteligência no Brasil, passa-se, então, a analisar as remissões que os documentos de Defesa e de Inteligência se fazem. A partir desse procedimento, busca-se responder às questões iniciais. Antes, porém, da análise intertextual propriamente dita, será apresentado um resumo da PNI e da ENINT.

\title{
PARTE 3 - POLÍTICA NACIONAL DE INTELIGÊNCIA (PNI), ESTRATÉGIA NACIONAL DE INTELIGÊNCIA (ENINT) E OS NOVOS DOCUMENTOS DE DEFESA
}

\author{
PNI e ENINT
}

Em linhas gerais, a PNI fixada em 2016: a) apresenta os conceitos de Atividade de Inteligência, Inteligência e Contrainteligência; b) define os pressupostos da atividade (obediência à Constituição Federal e às Leis; atividade de Estado; atividade de assessoramento oportuno; atividade especializada; conduta ética; abrangência; caráter permanente); c) correlaciona Estado, Sociedade e Inteligência (ameaças à segurança da sociedade e do Estado demandam ações preventivas); d) analisa os ambientes internacional e nacional, ressaltando que a complexidade global não permite clara diferenciação de aspectos internos e externos na identificação da origem das ameaças; menciona a necessidade de sintonia com a Política Externa Brasileira, com a Política de Defesa Nacional e com a Estratégia Nacional de Defesa; e) elenca como instrumentos da Inteligência atos normativos, instituições, métodos, processos, ações e recursos, como o Plano Nacional de Inteligência, a Doutrina Nacional de Inteligência, o Sisbin, entre outros); f) estabelece as principais ameaças com potencial capacidade de pôr em perigo a integridade da sociedade e do Estado (espionagem, sabotagem, interferência externa, ações contrárias à soberania nacional, ataques cibernéticos, terrorismo, atividades ilegais envolvendo bens de uso dual e tecnologias sensíveis, armas de destruição em massa, criminalidade organizada, corrupção, ações contrárias ao Estado Democrático de Direito); g) fixa os objetivos da Inteligência Nacional (avaliações de conjuntura; identificação de ameaças e riscos; neutralização de ações adversas; proteção de setores sensíveis; conscientização da sociedade sobre a atividade de inteligência); h) dá as diretrizes para a atividade de inteligência no país: prevenir ações de espionagem; ampliar a capacidade de detectar, acompanhar e informar sobre ações adversas aos interesses do Estado no exterior; prevenir ações de sabotagem; expandir a capacidade operacional da Inteligência no espaço cibernético; compartilhar dados e conhecimentos; ampliar a confiabilidade 
do Sisbin; expandir a capacidade operacional de Inteligência; fortalecer a cultura de proteção de conhecimentos; cooperar na proteção das infraestruturas críticas nacionais; e cooperar na identificação de oportunidades ou áreas de interesse para o Estado brasileiro.

Por seu turno, a essência da ENINT aprovada em 2017 pode ser compreendia avaliando seus quatro eixos estruturantes que se subdividem em dez desafios por sua vez desdobrados em 33 objetivos estratégicos. O primeiro eixo - atuação em rede - é organizado em dois desafios: a) fortalecimento da atuação integrada e coordenada da atividade de inteligência; e b) fortalecimento da cultura de proteção do conhecimento e de preservação do sigilo. Para responder ao desafio "a" são estabelecidos três objetivos: 1) aprimorar os processos e protocolos para comunicação e compartilhamento de informações; 2) mapear e gerenciar os principais processos a serem realizados no Sisbin; e 3) definir e regular critérios para atuação conjunta e coordenada no âmbito do Sisbin. Para responder ao desafio "b" são estabelecidos outros três objetivos: 1) criar protocolos conjuntos para proteção de conhecimentos sensíveis; 2) aperfeiçoar o processo de gestão de riscos; e 3) fomentar a cultura de proteção do conhecimento na sociedade. O segundo eixo - tecnologia e capacitação - é contemplado por três desafios: a) maior utilização de tecnologias de ponta, especialmente no campo cibernético; b) intensificação do uso de tecnologias de tratamento e análise de grandes volumes de dados (Big Data e Analytics); e c) ampliação e aperfeiçoamento do processo de capacitação para atuação na área de inteligência. Quatro objetivos buscam responder ao desafio "a": 1) ampliar a capacidade do Estado na obtenção de dados por meio da inteligência cibernética; 2 ) fortalecer a capacidade de pesquisa e desenvolvimento em tecnologia da informação e comunicação (TIC); 3) aprimorar a capacidade de desenvolver e implementar criptografia de Estado; 4) modernizar a infraestrutura de tecnologia da informação e comunicação (TIC). Três objetivos dimensionam a forma de intensificar o uso de Big Datas (desafio "b”): 1) ampliar a capacidade de obtenção e análise de grandes volumes de dados estruturados e não estruturados; 2) aprimorar a estruturação e o compartilhamento de bases de dados de inteligência; e 3) promover a interoperabilidade de bases de dados de interesse em nível nacional. Outros quatro objetivos são elencados para atender ao desafio "c": 1) promover a integração entre as Escolas de Governo para ampliar a oferta de cursos relacionados à inteligência e estruturar capacitações conjuntas; 2 ) estabelecer processo de gestão por competências para capacitação em inteligência; 3) fortalecer a educação a distância (EAD); e 4) promover a qualificação técnica para proteção e exploração do campo cibernético. 
A projeção internacional, que constitui o terceiro eixo estruturante, é dimensionada em dois desafios: a) ampliação da internacionalização da atividade de inteligência brasileira; e b) apoio ao fortalecimento da inserção do país do cenário internacional. Estabelece-se que o desafio "a” será superado por meio de quatro objetivos: 1) aumentar a representação da atividade de inteligência no exterior; 2 ) incrementar a interação do Sisbin com os demais sistemas de inteligência em temas de interesse; 3) aperfeiçoar a qualificação de adidos e demais agentes diplomáticos; e 4) aumentar a participação em fóruns, eventos e encontros internacionais. Também quatro objetivos são estabelecidos para o desafio "b": 1) ampliar as redes de parcerias e incrementar os acordos de cooperação internacional; 2) apoiar as instituições brasileiras em sua atuação no exterior; 3) ampliar o intercâmbio de informações entre os órgãos brasileiros com atuação no exterior; e 4) consolidar a atividade de inteligência em questões externas estratégicas. O último eixo - segurança do Estado e da sociedade - é organizado em três desafios: a) apoio ao combate à corrupção, ao crime organizado, aos ilícitos transnacionais e ao terrorismo; b) monitoramento e enfrentamento eficaz de ações adversas contra interesses nacionais; e c) aprimoramento da legislação para a atividade de inteligência. $\mathrm{O}$ desafio "a" é respondido com três objetivos: 1) estabelecer temas prioritários para produção de conhecimentos referentes às seguintes ameaças: corrupção, crime organizado, ilícitos transnacionais e terrorismo; 2) aprimorar os meios de compartilhamento de informações sobre corrupção, crime organizado, ilícitos transnacionais e terrorismo; e 3) criar protocolos específicos para atuação integrada do SISBIN em relação a corrupção, crime organizado, ilícitos transnacionais e terrorismo. Ao desafio "b" são estabelecidos três objetivos: 1) identificar os principais temas de interesse nacional para defesa contra ações adversas externas; 2) estabelecer sistema de alerta para prevenção de potenciais ações adversas; e 3) criar protocolos específicos para atuação integrada visando a neutralização de ações adversas. Por fim, dois objetivos respondem ao desafio "c": 1) acompanhar e apoiar o processo legislativo nos temas de interesse da atividade de inteligência e 2) aperfeiçoar o marco legal da atividade de inteligência.

Numa primeira mirada, os resumos da PNI e da ENINT permitem fazer algumas afirmações gerais: $1^{\circ}$ ) os desafios elencados pela ENINT demonstram a preocupação brasileira com o aperfeiçoamento da atividade de inteligência enquanto organização (estruturas funcionais) e enquanto atividade ou processo (meios), pois o produto (conhecimento produzido a partir de informações processadas) parece não estar se apresentando como o desejado; $2^{\circ}$ ) alguns objetivos estratégicos da ENINT apresentam-se como respostas às recomendações da CPI da Espionagem, por exemplo, aqueles 
relacionados ao aprimoramento da legislação de inteligência, à eficácia da contrainteligência e ao aumento de investimento em tecnologias de ponta e em capacitação de pessoal; $3^{\circ}$ ) o eixo estruturante 'projeção internacional' apresenta-se como resposta do Brasil a um cenário internacional já descrito na introdução deste artigo, além de sugerir também a convergência de visões da Defesa e da Inteligência no que diz respeito a destacar o papel que a Diplomacia tem em suas políticas e estratégias nacionais; $4^{\circ}$ ) do desafio de combater a corrupção, o crime organizado, os ilícitos transnacionais e o terrorismo (primeiro desafio do quarto eixo estruturante) deduz-se que tenha sido uma maneira de incorporar em âmbito nacional os compromissos já então assumidos pelo Brasil ao tornar-se signatário das Convenções de Palermo e de Mérida; desse desafio também se pode deduzir a intenção da Abin de assumir maior protagonismo no combate à corrupção no país, ao lado do Ministério Público e da Procuradoria Geral da República; $5^{\circ}$ ) no caso da PNI, três das onze ameaças elencadas (Espionagem, Ações contrárias à Soberania Nacional e Ataques cibernéticos) estão em direta confluência com as principais preocupações relatadas nas minutas da PND, da END e do LBDN: ambiente cibernético, gestão da informação e soberania nacional. Tais preocupações constituem-se nos principais pontos de intersecção entre os documentos de Defesa e Inteligência, como se verá a seguir.

\section{Inter-relações entre a PNI, a ENINT e os Novos Documentos de Defesa}

A análise dos Novos Documentos de Defesa do Brasil (minutas) permite deduzir que são três as principais formas por meio das quais a Defesa aborda a Atividade de Inteligência: $1^{\circ}$ ) na preocupação com o ambiente cibernético; $2^{\circ}$ ) na preocupação com a gestão da informação; e $3^{\circ}$ ) na preocupação com a soberania nacional. Os três aspectos estão interligados e refletem a inquietação contemporânea dos Estados com as novas tecnologias da informação e comunicação, que potencializaram ações lesivas variadas, possíveis de efetivação fora do território físico soberano da nação atacada. Tais ações efetivadas a longa distância enfatizaram a importância do ambiente virtual, dos fluxos informacionais de toda espécie e da necessidade de reconsiderar o conceito clássico de soberania nacional (o estritamente territorial).

A primeira abordagem (preocupação com o ambiente cibernético) é a que está mais disseminada nos três documentos de Defesa analisados, aparecendo de modo explícito: a) como contexto da PND no âmbito nacional [Amplo espectro de possibilidades no ambiente cibernético requer especial atenção $\grave{a}$ segurança e à defesa desse espaço virtual [...] (item 2.2.17)] e internacional $[$ A configuração internacional $[\ldots]$ gera tensões e instabilidades $[\ldots]$ que 
tendem a incrementar a guerra irregular [...] híbrida (item 2.3.2)]; b) como fundamento da END [As forças devem operar em rede na era da informação (item 3.3)]; e c) como um dos três setores estratégicos da Defesa [Nuclear, Cibernético e Espacial (3.3.5 - END)], setor esse desmembrado na criação do Comando de Defesa Cibernética, Centro de Defesa Cibernética e Escola Nacional de Defesa Cibernética, ativados em 2016 (páginas 57 e 58 do LBDN)]. Embora já registrada nos documentos de 2012, a preocupação com o ambiente cibernético aumentou graças possivelmente aos fatos ocorridos em 2013.

A segunda abordagem (preocupação com a gestão da informação) quase se mescla com a própria atividade de inteligência na medida em que obter e analisar dados e informações e produzir e difundir conhecimentos é um processo cuja essência está exatamente em como se faz a gestão da informação. A END entende a Gestão da Informação como uma das capacidades nacionais de Defesa, ou seja, como uma expressão do Poder Nacional, assim o país deve garantir a obtenção, produção e a difusão dos conhecimentos necessários à coordenação e ao controle dos meios de que dispõe a Nação, proporcionando o acesso à inteligência aos tomadores de decisão e aos responsáveis pelas áreas de Segurança Pública e de Defesa Nacional. Por esse amálgama entre Defesa e Inteligência, a END registra justamente que o Sisbin é a estrutura principal da capacidade de Gestão da Informação, reconhecendo, dessa forma, mais do que a contribuição da Defesa para ele, a importância dele - Sisbin - para o reforço do Poder Nacional.

A terceira abordagem (preocupação com a soberania nacional) parcialmente realça o reconhecimento por parte da Defesa de que o território físico (com suas expressões aérea e marítima) já não é circunscrição suficiente para delimitar a soberania nacional, considerando as chamadas territorialidades virtuais. Nesse sentido, a END reconhece o fortalecimento do Sisbin como uma ação de consolidação do Poder Nacional para garantir a soberania, o patrimônio nacional e a integridade territorial (AED-5, página 33). Por sua vez, o LBDN destaca o Sistema Nacional de Mobilização (Sinamob) como fundamental para estimular o fluxo de informações entre os órgãos dele integrantes. O Subsistema Setorial de Mobilização de Inteligência, sob a direção do GSI, funciona como órgão de direção setorial do Sinamob. Tais sistemas visam a que o fluxo informacional existente na Defesa se amplie para todo o corpo estratégico do Estado de modo a facilitar o processo decisório. A ênfase dada pelo LBDN-2016 ao Sisbin pode ser dimensionada pela estrutura de camadas que o documento descreve: os Centros de Inteligência da Marinha (CIM), do Exército (CIEx) e da Aeronáutica (CIAER) produzem informação processada para atendimento da própria demanda militar, mas integram, junto com as Forças Singulares, também o 
Sistema de Inteligência de Defesa (Sinde), cuja função é subsidiar o Sisbin. O fluxo informacional é, portanto, constante e agrega dados civis e militares, locais e regionais, nacionais e internacionais. Por essa constância, a PNI, ao considerar a Inteligência como uma atividade perene, que deve confundir sua existência com a do Estado ao qual serve, estabelece mais do que pontos de contato com a Defesa (via Sisbin), elevando-a a uma relação simbiótica, já que a necessidade de assessorar o processo decisório (Inteligência) e de salvaguardar os ativos estratégicos da Nação (Defesa) seria premente em situações de paz, de conflito ou de guerra.

\section{CONCLUSÃO}

$\mathrm{O}$ artigo procurou estruturar-se de modo a responder três questões essenciais: i) como a Atividade de Inteligência é abordada nos Novos Documentos de Defesa do Brasil? ii) Como a Defesa propõe-se a cooperar e interagir com a Atividade de Inteligência? iii) Como a Atividade de Inteligência propõe-se a cooperar e interagir com a Defesa? A formulação de tais questões adveio do debate a propósito da atualização dos documentos de Defesa do Brasil. Antes de propriamente responder ao 'como', o artigo procurou esclarecer as razões pelas quais a atividade de inteligência passou a recompor a centralidade da agenda internacional (sequência de atentados atípicos contra países do chamado 'mundo ocidental'); também procurou mostrar a interligação atual entre prevenção de atentados, financiamento ao terrorismo e enfrentamento de crimes transnacionais, com destaque para as convenções internacionais de Palermo e Mérida; especificamente no caso brasileiro, o artigo salientou as visões distintas que existem sobre a atividade de inteligência, destacando a proximidade da atividade com a ação repressora durante o regime autoritário e o desafio da atividade em se tornar ágil e transparente na democracia. Considerando igualmente importante, o artigo assinalou a função de nexo que a atividade de inteligência faz entre o âmbito nacional e o internacional (cooperações e compartilhamento de informações) e entre Diplomacia, Segurança e Defesa, dinamizando o fluxo de conhecimentos estratégicos com vistas a garantir a eficácia do processo decisório. Com base nessa contextualização e nesses pressupostos, o artigo então conclui que os Novos Documentos de Defesa, ao contrário da versão de 2012, insere a atividade de inteligência de Estado como central na política e estratégia nacionais de Defesa, reafirmando assim a hipótese de que a informação, seus meios de obtenção e sua transformação em conhecimento, numa sociedade em rede, constituem práticas imprescindíveis - e mais eficazes que estratégias militares convencionais - para enfrentar ameaças atípicas, seja em relação a ilícitos, seja 
em relação ao terrorismo. A forma principal por meio da qual se observa a abordagem da Atividade de Inteligência nos Novos Documentos de Defesa é a menção e valorização do Sisbin, considerado um sistema primordial para enfrentar os desafios do ambiente cibernético, garantir a segurança na gestão da informação estatal e preservar a soberania nacional física e virtualmente.

Em relação à maneira que a Defesa propõe-se a cooperar e interagir com a Inteligência, nota-se o reconhecimento por parte do setor de Defesa da relativa insuficiência de seus quadros no envolvimento com atividade de inteligência, especialmente fora do país. Especificamente os dados sobre adidos trazidos pela minuta do LBDN sugerem que uma das formas com que a Defesa quer favorecer cooperação e interação com a Inteligência é por meio do aumento das adidâncias no exterior. $\mathrm{O}$ aumento do número de adidos militares, associado à diminuição de militares em missão de paz, insinua a mudança de prioridades no setor de Defesa dos anos 2012 para 2016. Uma dessas prioridades, combinada, por exemplo, com um distanciamento relativo do arranjo BRICS, é a valorização da atividade de inteligência brasileira em arranjos cooperativos principalmente com os países industrializados ocidentais. A análise dos Novos Documentos também mostra que a Defesa procura expandir sua capacidade de proteção de dados sensíveis e, para tanto, reconhece a fragilidade de apenas fazê-lo no nível militar, já que lacunas em qualquer parte do sistema de proteção de dados fragiliza todo o sistema.

Da perspectiva da Atividade de Inteligência, a PNI e a ENINT são menos implícitas nas formas de registrar como pretendem cooperar e interagir com a Defesa. A PNI o faz ao ressaltar o ambiente cibernético, a gestão da informação e a soberania nacional, aspectos diretamente ligados à Defesa. A ENINT o faz em vários momentos, como quando registra o objetivo de integrar a capacitação de inteligência entre Escolas de Governos, ou quando propõe qualificar adidos e agentes diplomáticos lotados no exterior, ou ainda quando registra a intenção de consolidar a atividade de inteligência em questões externas estratégicas. Tais registros coadunam-se com a perspectiva 'para fora' que a Defesa, segundo os Novos Documentos, parece ter agora, diferentemente da visão 'para dentro’ que os documentos de 2012 traziam.

As leituras e cotejamentos realizados entre documentos de Defesa e Inteligência mostram, por fim, que, após a formalização em 1999 do Sisbin, da Abin e do Ministério da Defesa, tem existido uma cada vez maior sinergia entre a Defesa e a Inteligência no Brasil. Isso confirma a histórica filiação da inteligência com o Policiamento Interno (Segurança), a Diplomacia (Política Externa) e o Fazer a Guerra (Defesa). Há, no entanto, uma mu- 
dança significativa em termos de maior cooperação Defesa-Inteligência nas minutas dos Novos Documentos de Defesa de 2016, informação não evidente em 2012. Por outro lado, maior integração implica também riscos de surgimento de incompatibilidades entre setores que podem ver suas atribuições diluídas um no outro, descaracterizando a ambos, como pode ser o caso da criação de uma Agência Brasileira de Inteligência de Sinais e do estabelecimento de uma Política Nacional de Inteligência de Sinais, ainda difícil de avaliar se futuramente ligados exclusivamente ao Gabinete de Segurança Institucional (Abin) ou ao Ministério da Defesa (Sinde).

\section{REFERÊNCIAS}

Brasil. 1999. Lei $n^{\circ}$ 9. 883, de 7 de dezembro de 1999. Institui o Sistema Brasileiro de Inteligência, cria a Agência Brasileira de Inteligência - ABIN, e dá outras providências. Brasília.

2002. Decreto $n^{\circ} 4.376$, de 13 de setembro de 2002. Dispõe sobre a organização e o funcionamento do Sistema Brasileiro de Inteligência, instituído pela Lei n 9. 883/1999, e dá outras providências. Brasília.

2003. Decreto $n^{0} 4.872$, de 6 de novembro de 2003. Dispõe nova redação aos artigos $4^{\circ}, 8^{\circ}$ e $9^{\circ}$ do Decreto ${ }^{\circ} 4.376$, de 13 de setembro de 2002 , que dispõe sobre a organização e o funcionamento do Sistema Brasileiro de Inteligência, instituído pela Lei n 9. 883, de 7 de dezembro de 1999. Brasília.

2008. Decreto $n^{\circ}$ 6. 540, de 19 de agosto de 2008. Altera e acresce dispositivos ao Decreto $n^{\circ}$ 4. 376/2002, que dispõe sobre a organização e o funcionamento do Sistema Brasileiro de Inteligência, instituído pela Lei no 9. 883/1999. Brasília.

2008. Decreto $n^{\circ}$ 6. 703, de 18 de dezembro de 2008. Aprova a Estratégia Nacional de Defesa, e dá outras providências. Brasília.

Ministério da Defesa. 2012. Política Nacional de Defesa. Estratégia Nacional de Defesa. Brasília: Ministério da Defesa.

Ministério da Defesa. 2012. Livro Branco da Defesa Nacional. Brasília: Ministério da Defesa.

Comissão Nacional da Verdade. 2014. Relatório / Comissão Nacional da Verdade. Recurso eletrônico. Brasília: CNV. (Relatório da Comissão Nacional da Verdade; v. 1).

CPI da Espionagem. 2014. Relatório Final. Comissão Parlamentar de Inquérito destinada a investigar a denúncia de existência de um sistema de espio- 
nagem, estruturado pelo governo dos Estados Unidos, com o objetivo de monitorar e-mails, ligações telefônicas, dados digitais, além de outras formas de captar informações privilegiadas ou protegidas pela Constituição Federal. Brasília: Câmara dos Deputados.

. Ministério da Defesa. 2016. Política Nacional de Defesa. Estratégia Nacional de Defesa. Versão sob apreciação do Congresso Nacional (Lei Complementar 97/1999, art. $\left.9^{\circ}, \S 3^{\circ}\right)$. Brasília: Ministério da Defesa.

Ministério da Defesa. 2016. Livro Branco de Defesa Nacional. Versão sob apreciação do Congresso Nacional (Lei Complementar 97/1999, art. $9^{\circ}$, $3^{\circ}$ ). Brasília: Ministério da Defesa.

2016. Decreto $n^{\circ}$ 8. 793, de 29 de junho de 2016. Fixa a Política Nacional de Inteligência. Brasília.

Institucional.

2017. Estratégia Nacional de Inteligência. Brasília: Gabinete de Segurança

Cepik, Marco A. C. 2001. Serviços de Inteligência: Agilidade e Transparência como Dilemas de Institucionalização. Tese de doutorado, Instituto Universitário de Pesquisas do Rio de Janeiro, Rio de Janeiro.

Gonçalves, Joanisval Brito. 2008. Sed Quis Custodiet Ipso Custodes? O Controle da Atividade de Inteligência em Regimes Democráticos: os Casos de Brasil e Canadá. Tese de doutorado, Pós-Graduação em Relações Internacionais, Instituto de Relações Internacionais, Universidade de Brasília, Brasília.

Herz, John H. 1950. Idealist Internationalism and the Security Dilema. World Politics, 2.

Kent, Sherman. 1949. Strategic Intelligence for American World Policy. Princeton: Princeton University Press.

Oliveira, Marcel Carrijo de. 2010. A Democratização Tardia da Inteligência na Argentina e no Brasil. Dissertação de Mestrado, Universidade de Brasília, Brasília.

Platt, Washington. 1974 [1957]. A Produção de Informações Estratégicas. Rio de Janeiro: Agir/Bibliex.

Raza, Salvador Ghelfi. 2004. Para além dos Livros Brancos de Defesa. In: Brigagão, Clóvis; Proença Júnior, Domício (Org. ). Paz e Terrorismo: Textos do Seminário Desafios para a Política de Segurança Internacional: Missões de Paz da ONU, Europa e América. São Paulo: Hucitec. 334-356. 
Ugarte, José Manuel. 2002. Control Público de la Actividad de Inteligencia: Europa y América Latina, una Visión Comparativa. Congresso Internacional "PostGlobalización: Redefinición de la Seguridad y la Defensa Regional en el Cono Sur", Centro de Estudios Internacionales para el Desarrollo, Buenos Aires.

Volkman, Ernest. 2013. A História da Espionagem: o Mundo Clandestino da Vigilância, Espionagem e Inteligência, desde os Tempos Antigos até o Mundo pós-9/11. São Paulo: Editora Escala. 


\section{A ATIVIDADE DE INTELIGÊNCIA NOS NOVOS DOCUMENTOS DE DEFESA DO BRASIL}

\section{RESUMO}

O artigo compara os documentos brasileiros de Defesa de 2016 (minutas/ propostas) com os de 2012 (oficiais), associando-os com a Política Nacional de Inteligência (2016) e a Estratégia Nacional de Inteligência (2017), objetivando identificar como a Atividade de Inteligência é abordada pela Defesa e como uma área propõe cooperar e interagir com a outra.

Palavras-chave: Brasil, Atividade de Inteligência; Novos Documentos de Defesa; Documentos de Inteligência.

\section{ABSTRACT}

The article compares the Brazilian Defense documents of 2016 (drafts/ proposals) with those of 2012 (official), associating them with the National Intelligence Policy (2016) and the National Intelligence Strategy (2017), in order to identify how the Intelligence Activity is addressed by Defense and how one area proposes to cooperate and interact with the other.

Keywords: Brazil; Intelligence Activity; New Defense Documents; Intelligence Documents. 